\title{
FONTES PARA O ESTUDO DA POBREZA NO NORTE DE PORTUGAL OITOCENTISTA
}

\author{
Alexandra Patrícia LoPes Esteves \\ Universidade Católica Portuguesa \\ CITCEM-Universidade do Minho
}

Recibido: $14 / 12 / 2013$

Aceptado: 07/06/2014

RESUMO: A nossa comunicação incide nas fontes que permitem conhecer a pobreza e os pobres do Norte de Portugal, bem como os mecanismos de apoio utilizados pelo Estado e pelas instituições assistenciais com vista a atenuar as dificuldades dos mais carenciados. Os fundos documentais dos governos civis e das administrações do concelho assumem uma importância cada vez maior para os historiadores sociais, a par da documentação produzida pelas misericórdias e outras irmandades. No caso particular de Viana do Castelo, partir de 1855 , os jornais tornam-se também uma fonte de informação de inegável interesse para compreender a sociedade oitocentista e os seus problemas. Consideramos que uma visão mais completa e abrangente da pobreza será conseguida através do cruzamento de fontes provenientes de diferentes fundos documentais.

PALAVRAS-CHAVE: Fontes, pobreza, assistência, arquivos, Viana do Castelo.

\begin{abstract}
Our communication focuses on sources that allow knowing poverty and the poor in northern Portugal, as well as the support mechanisms used by state and welfare institutions to mitigate the difficulties faced by poorest. The documental funds of civilian governments and administrations of the county are of increasing importance to social historians, along with the documentation produced by the Misericórdias and other brotherhoods. In the particular case of Viana do Castelo, from 1855, the newspapers also become a source of information of undeniable interest to understand the nineteenth-century society and its problems. We believe that a more complete and comprehensive poverty will be achieved through the intersection of sources from different documental funds.
\end{abstract}

KEYWORDS: Sources, poverty, assistence, archives, Viana do Castelo.

Os estudos realizados no âmbito da historiografia portuguesa, em particular os respeitantes ao Norte de Portugal, têm demonstrado que os universos da marginalidade e da pobreza caminham lado a lado, quando não se cruzam e 
entrelaçam percursos ${ }^{1}$. São os pobres que preponderam nos espaços prisionais, deambulam entre a mendicidade e a vagabundagem, são sujeitos a um controlo apertado e culpabilizados por diversas enfermidades endémicas que assolaram o Velho Continente no século XIX. Neste contexto, a burguesia, a classe cada vez mais dominante, adota uma atitude de desconfiança em relação aos mais desfavorecidos, imputando-lhes um comportamento laxista, ocioso, imoral e promíscuo, pelo que apostam na alteração dos valores pelos quais, supostamente, se orienta esse grupo social ${ }^{2}$.

No tocante ao labor investigativo e à produção científica da historiografia portuguesa, importa salientar que o estudo da pobreza e dos pobres tem assumido um destaque maior do que os trabalhos realizados na área da marginalidade, sobretudo no atinente à Idade Moderna. Quanto ao período contemporâneo, quer o estudo da pobreza, quer da marginalidade, ainda têm um longo percurso a desbravar, apesar do aumento do número de obras que incidem nesta época.

Em Portugal, o estudo da problemática da pobreza e dos dispositivos adotados ao longo dos tempos para a minimizar e combater, tem-se materializado, essencialmente, em trabalhos sobre as instituições que, no âmbito das suas incumbências, se propõem auxiliar os mais necessitados ${ }^{3}$. Esta via revelou-se um instrumento

\footnotetext{
${ }^{1}$ Em Portugal, uma das áreas mais trabalhadas neste domínio tem sido a da assistência prestada aos presos pobres. Trata-se de uma investigação de grande relevância, dado o conhecimento que tem possibilitado sobre os espaços e os quotidianos prisionais. Neste campo, salientamos os trabalhos produzidos por LOBO DE ARAÚJO, M. (1998): "Pobres nas malhas da lei: a assistência aos presos nas Misericórdias de Vila Viçosa e Ponte de Lima”. Cadernos do Noroeste, vol. 11 (2), pp. 83-114. Da mesma autora, (2000). Dar aos pobres e emprestar a Deus: as Misericórdias de Vila Viçosa e Ponte de Lima (séculos XVI-XVIII). Barcelos: Santa Casa da Misericórdia de Vila Viçosa; Santa Casa da Misericórdia de Ponte de Lima, pp. 249-266; 669-679. (2003). "O hospital do Espírito Santo de Portel na Época Moderna". Cadernos do Noroeste, Série História 3, 20, (1-2), pp. 386-387; (2006). "Na barra dos tribunais: os presos e a Misericórdia de Portel (séculos XVIXVII)". Congresso Internacional de História. Territórios, Culturas e Poderes. Atas, vol. I, Núcleo de Estudos Históricos, Universidade do Minho, Braga, pp. 303-318; (2008). A Misericórdia de Monção: fronteira, guerras e caridade (1561-1810), Braga, Misericórdia de Monção, pp. 293-303. ABREU, L. (1999). Memórias da alma e do corpo. A Misericórdia de Setúbal na Modernidade. Viseu: Palimage, pp. 427-430. FERREIRA CARDOSO, M. (2006).“A cadeia da Relação do Porto e a assistência prestada aos presos pela Misericórdia do Porto (1735-1740) ". Noroeste. Revista de História, 2, pp. 349-371. CASTRO, M. (2006). "Presos, enjeitados e meninos desamparados no programa assistencial da Misericórdia de Braga”. Noroeste. Revista de História, 2, pp. 373-404.

${ }^{2}$ Sobre a relação entre a pobreza e a doença veja-se ESTEVES, A. (2012)."La enfermedad como elemento de discriminación social, en el Norte de Portugal, a finales del siglo XIX y princpios del XX”. Estudios Humanísticos. História, pp. 289-308.

${ }^{3}$ De facto, são muitos os historiadores portugueses que se têm ocupado desta temática, pelo que se torna difícil mencionar o nome de todos os que produziram trabalhos sobre misericórdias, ordens terceiras, recolhimentos, hospitais e rodas.
} 
eficaz para a compreensão dos mecanismos assistenciais e para o conhecimento da pobreza em território luso, permitindo, inclusive, explicitar as mutações ocorridas neste domínio, resultantes das modificações das estruturas políticas, sociais e do quadro de valores que, em diferentes momentos históricos, foram norteando as sociedades. Todavia, não deixa de ser uma leitura parcial da pobreza, da assistência e da marginalidade, dado que permite rastrear apenas uma parte dos pobres: os que foram assistidos institucionalmente. Todos os demais, que não foram acolhidos pelas instituições, sucumbiram à miséria ou, quando bafejados pela fortuna, conseguiram sobreviver à custa da ajuda da família ou da vizinhança. Estes ficam remetidos ao anonimato, pelo menos no que diz respeito a tempos mais recuados. Tal facto decorre da ausência de fontes históricas, da qual resulta a invisibilidade de realidades às quais o historiador não pode aceder sem uma "rede" documental que o apoie. Por outro lado, a indigência e a marginalidade, embora possam ser considerados dois caminhos paralelos, o que tem sido corroborado pelos estudos elaborados sobre as prisões e a criminalidade, nem sempre se cruzam nem seguem a mesma direção. No entanto, se aceitarmos que o conceito de marginalidade se arroga a quem vive nas margens, então podemos estabelecer uma relação entre estes dois conceitos ${ }^{4}$.

As instituições que se destacaram pelo seu labor assistencial têm merecido a atenção da historiografia portuguesa, expressa na publicação de numerosos trabalhos. As obras sobre estas instituições de criação régia remontam a finais da centúria oitocentista e ao dealbar do século $\mathrm{XX}^{5}$. Foi sobretudo a partir da década de noventa do século passado que a história social se mobilizou no sentido de aprofundar os conhecimentos sobre as misericórdias e outras instituições de pendor assistencial, como confrarias, hospitais e ordens terceiras. Destacamos, muito particularmente, os trabalhos precursores, publicados em finais da década de noventa e início da centúria seguinte, de Ivo Carneiro de Sousa, Laurinda Abreu, Isabel dos Guimarães Sá, Maria Marta Lobo de Araújo e Maria Antónia Lopes, centrados, fundamentalmente, na época moderna ${ }^{6}$. Atualmente, trata-se de uma

\footnotetext{
${ }^{4}$ Sobre os marginais na Idade Média leia-se DUARTE, L. M. (1996)."De que falamos nós quando falamos de marginais? Portugal na Baixa Idade Média". Revista de Ciências Histórica, 11, pp. 55-68. RIBEIRO da SILVA, F. (1996). "Marginais e marginados à luz das Ordenações Filipinas". Revista de Ciências Históricas, 11, 69-76.Veja-se igualmente a obra de GEREMEK, B. (1995). A piedade e a forca. A História da miséria e da caridade na Europa. Lisboa: Terramar.

${ }^{5}$ È o caso da obra da autoria de Victor Ribeiro. RIBEIRO, V. (1902). A Santa Casa da Misericórdia de Lisboa. Elementos para a sua história (1498-1898). Lisboa: Real Academia das Sciencias. Do mesmo autor destacamos a obra (1907). História da beneficência pública em Portugal. Coimbra: Imprensa da Universidade. Para finais do século XIX, destaque-se a obra de GOODOLPHIM, C. (1897). As Misericórdias. Lisboa: Imprensa Nacional.

${ }^{6}$ De Ivo Carneiro de Sousa destacam-se os trabalhos: (1998). V Centenários das Misericórdias Portuguesas. Lisboa: CTT; (1999). Da Descoberta da Misericórdia à invenção das Misericórdias (1498-1525). Porto: Granito Editors \&Livreiros; (2003). A Rainha D. Leonor (1458-1525). Poder,
} 
área em clara expansão, verificável através da vasta obra científica que tem sido produzida, na sequência de congressos, colóquios e seminários, de projetos nacionais e internacionais, bem como de um crescente número de teses de mestrado e doutoramento referentes a diferentes regiões do país. Destaca-se, a nível nacional, o projeto Portugaliae Monumenta Misericordiarum, pela sua relevância na publicação de fontes e na elaboração de sínteses na introdução de cada volume.

No plano internacional, esta tendência de estudo cresceu na década de sessenta, quando a história social conheceu novos avanços, que se materializaram na publicação de obras sobre as minorias, os pobres e os marginais. Por exemplo, o contexto político, social e cultural francês, das décadas de sessenta e setenta, foi responsável pela atenção que a historiografia passou a conceder aos delinquentes, às crianças, às mulheres e aos presos ${ }^{7}$. O crescente protagonismo conseguido por esta área da história não se pode dissociar da Escola dos Annales, que alargou o conceito de fonte e permitiu que a história se tornasse permeável à influência e às metodologias de outras ciências, como a Sociologia, a História, a Antropologia e a Economia. Consequentemente, o campo da historiografia alarga-se e inclui no-

Misericórdia, Religiosidade e Espiritualidade no Portugal do Renascimento. Lisboa: Fundação Calouste Gulbenkian/FCT . De Isabel dos Guimarães Sá, entre outros trabalhos, ressalvamos: (1997). Quando o rico se faz pobre: Misericórdias, caridade e poder no Império Português, 15001800. Lisboa: Comissão Nacional para as Comemorações dos Descobrimentos Portugueses; (2001). As Misericórdias Portuguesas de D. Manuel I a Pombal. Lisboa: Livros Horizonte. (1996).”A assistência: as misericórdias e os poderes locais". in OLIVEIRA, C. (ed.). História dos Municípios e do Poder Local (dos finais da Idade Média à União Europeia). Lisboa: Círculo dos Leitores, pp. 136 - 142. (1996). "As confrarias e as misericórdias". In OLIVEIRA, C. (ed.). História dos Municípios e do Poder Local (dos finais da Idade Média à União Europeia). Lisboa: Círculo de Leitores, pp. 55-60. De Laurinda Abreu saliente-se (1990). Santa Casa da Misericórdia de Setúbal de 1500 a 1755: aspetos de sociabilidade e poder. Setúbal: Santa Casa da Misericórdia de Setúbal e (1999). Memórias da Alma e do Corpo - a Misericórdia de Setúbal na Modernidade. Viseu: Palimage. Da autoria de Maria Marta Lobo de Araújo sobressaem, nos primeiros anos do século XXI: (2000). Dar aos pobres em emprestar a Deus: as Misericórdias de Vila Viçosa e Ponte de Lima (séculos XVI-XVIII). Barcelos: Santa Casa da Misericórdia de Vila Viçosa/Santa Casa da Misericórdia de Ponte de Lima. (2000). Pobres, Honradas e Virtuosas: os dotes de D. Francisco e a Misericórdia de Ponte de Lima (1680-1850). Barcelos: Santa Casa da Misericórdia de Ponte de Lima. (2001). A confraria do Santíssimo Sacramento do Pico de Regalados (1731-1780). Vila Verde: ATHACA, Caixa de Crédito Agrícola Mútuo. De Maria Antónia Lopes: (2000). Pobreza, assistência e controlo social em Coimbra, 1750-1850, 2 vols.Viseu: Palimage. (2002). “As Misericórdias: de D. José ao final do século XX”. In PAIVA, José Pedro (dir.). Portugaliae Monumenta Misericordiarum 1. Fazer a história das Misericórdias. Lisboa: Universidade Católica/União das Misericórdias Portuguesas, pp. 79-117.

${ }^{7}$ Nestes domínios, destacam-se, na década de 70 do século XX, os trabalhos desenvolvidos por Michel Certau e B. Geremek. Confirme-se PETIT, Jacques-Guy (1998). "Los marginales en el centro de la historia". In VACA LORENZO, Ángel (ed.). Disidentes, Heterodoxos y Marginales en la História. Salamanca: Ediciones Universidad de Salamanca, p. 271. 
vos protagonistas: pobres, marginais, doentes, loucos, criminosos. Sobressaem, neste domínio, a historiografia francesa, com realce para os estudos de Michel Foucault e dos seus sucessores, e a historiografia anglo-saxónica, na qual começam a destacar-se nomes como E. H. Thompson e Eric Hobsbown ${ }^{8}$.

Em Portugal, os trabalhos sobre a pobreza e a marginalidade remontam a finais dos anos 80 e sobretudo aos anos $90^{9}$. Este atraso na realização de estudos no âmbito da história social repercute o contexto político que se estendeu até à Revolução de 25 de abril de 1974. Durante os cerca de quarenta anos de ditadura, a historiografia portuguesa foi condicionada na sua escrita e formulação, centrando-se, fundamentalmente, em temáticas de glorificação das épocas mais entusiásticas da gesta lusa. Por conseguinte, tempos menos auspiciosos ou dominados, segundo a perspetiva do regime, por ideologias perniciosas foram simplesmente ignorados. A monarquia constitucional e a república entram neste segmento, sendo, por isso, períodos suprimidos das páginas dos livros de História durante o Estado Novo.

Deste modo, no que respeita aos séculos XIX e XX, a historiografia portuguesa tem-se centrado mais no domínio político, económico e ideológico. Este pode ser um dos motivos invocados para explicar a existência de um certo desfasamento entre o elevado número de trabalhos produzidos em Portugal que se inserem no campo da história da pobreza e da assistência na época moderna, em comparação com o período contemporâneo, embora nos últimos anos se tenha registado um acréscimo. Podemos igualmente afirmar que o número de estudos sobre o período medieval também é menor quando comparado com a época moderna. Mas aqui invoca-se a questão das fontes, que não se coloca em relação à contemporaneidade ${ }^{10}$.

${ }^{8}$ Outros nomes e obras se destacam, como KING, S.: Poverty, Poverty and Welfare in England (1700-1850): a regional perspective, Manchester, Manchester University, 2000 e HINDLE, S.: On the parish? The Micro-Politics of Poor Relief in Rural England (1550-1750), Oxford, Oxford University Press, 2009.

${ }^{9}$ Sobre a pobreza, destaca-se a obra de Fernando da Silva Correia, com vários títulos, lançados na década de 50 do século passado. SILVA CORREIA, C. F.: "João Luís Vives e o renascimento da assistência", separada de $O$ Médico, 23, 1956. Do mesmo autor: Origens e formação das Misericórdias Portuguesas, Lisboa, Livros Horizonte, 1999. A assistência cristã desde o século IV ao século X, s.l., s.n., 1938); A assistência nos primeiros tempos do cristianismo, s.l., s.n., 1938. Os hospitais medievais portugueses, Lisboa, Imprensa Médica, 1943. Origens e formação das misericórdias portuguesas: estudos sobre a história da assistência, Lisboa, Henrique Torres, 1944. No caso do distrito de Viana do Castelo, podemos evocar o trabalho de CÉSAR ESTEVES, A.: Santa Casa da Misericórdia de Melgaço, Melgaço, Typ. Melgacense, 1957.

${ }^{10}$ Para o período medieval salientam-se os trabalhos de Maria José Tavares Ferro, como "Para o estudo do pobre em Portugal na Idade Média" Revista de História Económica e Social, n. ${ }^{\circ} 11$, 1983, pp. 29-54. Da mesma autora: Pobreza e Morte em Portugal na Idade Média, Lisboa, Editorial 
Dadas estas perspetivas, podemos seguramente afirmar que a história da pobreza, da assistência e da marginalidade, relativa ao período da monarquia constitucional portuguesa, em muitos aspetos está por fazer ${ }^{11}$. Não se afigura descabido dizer que existe um desequilíbrio entre o número de trabalhos publicados e as fontes disponíveis. Além do mais, reportamo-nos a um tempo de profundas mutações, quer no respeitante à vertente política, quer no referente ao quadro administrativo, que passa a funcionar segundo uma inspiração claramente francófo$\mathrm{na}^{12}$. Com a reforma administrativa, surgiram novas entidades, qualificadas como representantes do poder central, com amplos poderes em áreas muito diversas; o país foi dividido em distritos, que por sua vez foram divididos em concelhos e estes subdivididos em freguesias. À frente do distrito, fica o governador civil, anteriormente apelidado de administrador geral no Código Administrativo de 1836, a liderar o município aparece o administrador do concelho, coexistindo com a câmara municipal, e em cada freguesia surge a figura do regedor. A par da criação destas novas autoridades, foram organizados novos organismos administrativos:

Presença, 1989. CRUZ, A.: “A assistência na cidade do Porto e o seu termo durante a Idade Média", in A pobreza e a assistência aos pobres na Península Ibérica durante a Idade Média. Atas das $1^{a}$ S Jornadas Luso-espanholas de História Medieval, tomo 2, Lisboa, Faculdade de Letras, 1979, pp. 329-344. FONSECA, J.: "Para a história do associativismo no Alentejo medieval. A confraria e albergaria do Espírito Santo do Vimieiro (1282)", in A cidade de Évora, no 3, II série, 1998-1999, pp. 37-38. GONÇALVES, I.: "Formas medievais de assistência num meio rural estremenho.", in A pobreza e a assistência aos pobres na Península Ibérica durante a Idade Média. Atas das $1^{a}$ s Jornadas Luso-espanholas de História Medieval, tomo 2. Lisboa, Faculdade de Letras, 1979, pp. 438-454. MATA, Luís: Ser, Ter e Poder, O hospital do Espírito Santo de Santarém nos finais da Idade Média, Lisboa, Ed. Magno, 2000. MATTOSO, J.: "O ideal de pobreza e as ordens monásticas em Portugal durante os séculos XI-XIII." in A pobreza e a assistência aos pobres na Península Ibérica durante a Idade Média. Atas das $1^{a}$ S Jornadas Luso-Espanholas de História Medieval, tomo 2, Lisboa, Faculdade de Letras, 1979, pp. 637-669. BEIRANTE, M. A.: "Ritos alimentares em algumas confrarias portuguesas medievais.", in Atas do Colóquio Internacional Piedade Popular, Sociabilidades, Representações e Espiritualidade, Lisboa Terramar, 1999, pp. 559-579. Veja-se igualmente BEIRANTE, M. A.: Confrarias medievais portuguesas, Lisboa, Ed. A., 1990. Refira-se também os trabalhos de CRUZ COELHO, M. H.: "As confrarias medievais portuguesas: espaços de solidariedades na vida e na morte" in Cofradias, grémios, solidariedades en la Europa Medieval. XIX Semana de estúdios Medievales, Navarra, Dep. Educación y Cultura, 1992, pp. 149183. Da mesma autora "Assistência em Coimbra em tempos manuelinos. O hospital Novo", Biblos, 72, pp. 223-257.

${ }^{11}$ Confirme-se PAIVA, J. P.; Lopes, M. A. (Coord.): Portugaliae Monumenta Misericordiarum. Tradição e modernidade: o periodo da monarquia constitucional (1834-1910), vol. 8, Lisboa, União das Misericórdias, 2010.

${ }^{12}$ Sobre a evolução da divisão administrativa do território no período liberal leia-se OLIVEIRA, C.: "Os municípios no liberalismo monárquico constitucional", in OLIVEIRA, C. (dir.) História dos Municipios e Poder Local. [Dos finais da Idade Média à União Europeia], Lisboa, Círculos de Leitores, 1996, pp. 205-212. 
a nível distrital, o conselho de distrito e a junta geral administrativa do distrito; a nível da freguesia, a junta de paróquia. Se os magistrados eram cargos dependentes de nomeação, os elementos que integravam as câmaras municipais e as juntas de paróquia eram eleitos pelo povo ${ }^{13}$.

Às novas entidades administrativas foram conferidas competências importantes em matéria assistencial, o que revela a intenção do Estado liberal de dirigir o processo de controlo e, se possível, de erradicação da pobreza, através da formulação de um programa assistencialista que passaria pelo auxílio aos verdadeiros pobres e pela repressão daqueles que escolhiam a mendicidade como modo de vida. Deste modo, os falsos pobres e vadios deveriam ser punidos com a privação da liberdade e regenerados pelo trabalho. Salvas as devidas diferenças, tendia a aplicar-se o modelo de reclusão de pobres que existiu na época moderna, tendo em vista a sua reabilitação.

Num tempo de grande instabilidade, governadores civis, administradores dos concelhos e regedores eram elementos chave no processo, que se pretendia descentralizado, de fiscalização da pobreza. Segundo o disposto no Código Administrativo de 1836, cabia às juntas gerais de distrito determinar as quotas com que os concelhos deviam contribuir para o sustento dos expostos e em que locais se devia proceder à instalação das rodas ${ }^{14}$. As câmaras municipais, por sua vez, continuavam a ter a seu cargo a subsistência e a educação dos enjeitados e a elaboração dos regulamentos das rodas ${ }^{15}$. Saliente-se que, no século XIX, os grupos que mais facilmente resvalavam para uma situação de indigência eram os mesmos do período histórico anterior: crianças, mulheres, doentes, idosos e presos ${ }^{16}$.

As instituições que na época moderna se destacavam no auxílio aos mais carenciados conservavam essa função, embora acompanhadas por outras entretanto criadas pelo Estado liberal, e sujeitas a uma maior fiscalização por parte das entidades administrativas, nomeadamente em matéria financeira. As confrarias são exemplo disso mesmo. Os governos civis tinham competência para analisar as despesas efetuadas pelas irmandades e dissolver as mesas quando julgassem oportuno. Importa ainda assinalar o disposto no artigo $108 \S 5$ do Código Administrativo de 1836 , que conferia poderes ao governador civil para canalizar as verbas sobrantes das irmandades para os estabelecimentos que julgasse mais carenciados, o que na prática se traduzia numa clara ingerência na atividade as-

\footnotetext{
${ }^{13}$ Confirme-se Código Administrativo Portuguez, Lisboa, Imprensa Nacional, 1838.

${ }^{14}$ Ibidem, p. 35.

${ }^{15}$ Ibidem, p. 41.

${ }^{16}$ LOBO DE ARAÚJO, M. M.: Rituais de Caridade na Misericórdia de Ponte de Lima (séculos XVI-XIX), Ponte de Lima, Santa Casa da Misericórdia de Ponte de Lima, 2003.
} 
sistencial de misericórdias e confrarias. Portanto, hospitais, asilos e albergues ficaram igualmente sujeitos à ação inspetiva do governador civil, a quem também cabia velar pelo seu estado de conservação e pela realização das obras de melhoramento que fossem consideradas indispensáveis ${ }^{17}$. A superintendência dos governos civis sobre os organismos e instituições pias está igualmente patente no normativo de 1842, que estabelecia que os bens das irmandades ilegalmente constituídas deviam passar para as mãos das juntas de paróquia ${ }^{18}$. As confrarias passavam ainda a ser obrigadas, por determinação da respetiva junta, a contribuir para a paróquia, de acordo com os seus rendimentos ${ }^{19}$. Com estes procedimentos procurava-se evitar administrações despesistas, não causando, no entanto, perturbações significativas na atividade assistencial.

As juntas de paróquia, enquanto comissões de beneficência pública, assumiam, a nível da freguesia, importantes competências: listar, juntamente com o regedor, as pessoas que deviam beneficiar de ajuda pública e requerer o ingresso dos classificados como carecentes de amparo em hospitais e asilos, em conformidade com o disposto nos normativos vigentes. Tinham ainda a prerrogativa de promover medidas que visassem a repressão da mendicidade, em particular dos falsos pobres, e fiscalizar as amas que tinham a seu cargo os expostos ${ }^{20}$. Por sua vez, os governos civis, cujas competências incluíam a manutenção da ordem e da tranquilidade pública, deviam fazer cumprir os regulamentos respeitantes aos mendigos, vagabundos e prostitutas.

No Estado liberal, além dos homens da justiça, outras entidades intervinham nas instituições prisionais ${ }^{21}$. Se já no Antigo Regime cabia às câmaras municipais promover e financiar as reparações das cadeias e, em alguns casos, nomear os carcereiros, com o advento do liberalismo e a instauração de uma nova ordem administrativa, também os administradores dos concelhos e os governadores civis passaram a assumir responsabilidades nesse âmbito, nomeadamente no funcionamento das cadeias e na organização do sustento dos presos pobres. Era precisamente nestes dois domínios que atuavam os seus representantes, ou seja, a nível concelhio os administradores dos concelhos, que eram superintendidos, a

\footnotetext{
${ }^{17}$ Código Administrativo Portuguez...op. cit., p. 65.

${ }^{18}$ Código Administrativo Portuguez de 1842, Coimbra, Imprensa da Universidade, 1849, pp. 75-76.

${ }^{19}$ Ibidem, p. 49.

${ }^{20} \mathrm{Idem}$.

${ }^{21}$ Sobre as alterações impostas pelo estado liberal a nível da organização administrativa veja-se REIS MARQUES, M.: "Estruturas jurídicas", in MATTOSO, J. (dir.), História de Portugal, vol. 5, Lisboa, Círculo de Leitores, 1993, pp. 171-175.
} 
nível distrital, pelos governadores civis ${ }^{22}$. A estes cabia, de acordo com o Código Administrativo de 1836, assegurar o sustento dos presos e o bom funcionamento das prisões, e aos administradores dos concelhos inspecioná-las e também prover a subsistência dos mais carenciados ${ }^{23}$. Pela circular de 29 de maio de 1837, as juntas gerais de distrito ficaram encarregadas de averiguar os locais mais apropriados para a instalação das cadeias e os meios mais eficazes para garantir o mantimento dos reclusos considerados indigentes ${ }^{24}$. O Código Administrativo de 1842 continuava a incumbir os governos civis de zelarem pelo melhoramento das prisões e pela organização do sustento dos presos pobres. A inspeção das cadeias era atribuída principalmente às autoridades judiciais, cabendo às autoridades administrativas a fiscalização das detenções em flagrante delito e nos casos em que não se exigia formulação prévia de culpa. Estipulava ainda que o fornecimento dos mantimentos dos presos fosse decidido por arrematação, de acordo com o estabelecido no Regulamento das Cadeias de $1843^{25}$.

Pelo decreto de 28 de agosto de 1845 , a administração das cadeias e o sustento dos presos pobres passou para as mãos das autoridades judiciais, ao estabelecer que todos os atos estabelecidos nos Capítulos 9. ${ }^{\circ}$ e $10 .^{\circ}$ do referido Regulamento deixavam de ser incumbência das autoridades administrativas para passarem a ser obrigação das autoridades judiciais. Estes capítulos referiam-se precisamente à organização da alimentação dos reclusos indigentes ${ }^{26}$.

Mais tarde, pela lei de um de julho de 1867, que incide na reforma penal e das prisões, foi clarificado o exercício de jurisdições com a divisão dos estabelecimentos prisionais em cadeias penitenciárias, distritais e comarcãs, com modalidades de gestão distintas ${ }^{27}$. Para as cadeias distritais previa a criação de comissões administradoras, compostas pelo governador civil do distrito, que seria o

${ }^{22}$ Pela portaria de 30 de junho de 1838, cabia aos governos civis a organização do sustento a conceder aos presos pobres nas localidades onde não existissem Misericórdias, de acordo com o artigo $108 .^{\circ}, \S 5 .^{\circ}$ do Código Administrativo. Collecção de Leis e outros documentos officiais publicados no ano de 1838, 8. ${ }^{\text {a }}$ série, Lisboa, Imprensa Nacional, 1838, p. 303.

${ }^{23}$ ANTT, Ministério do Reino, 3. ${ }^{a}$ Repartição, Cadeias 1838-1843, Maço 1992, não paginado. Confira-se o art. ${ }^{\circ} 109, \S 5$ do Código Administrativo de 1836. Código Administrativo Portuguez,

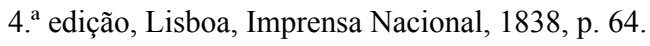

${ }^{24}$ Collecção de Leis e outros documentos officiais publicados no $1^{\circ}$ semestre de 1837, Sétima Série, Lisboa, Imprensa Nacional, 1837, p. 313.

${ }^{25}$ Código Administrativo..., op. cit., p. 78.

${ }^{26}$ Collecção Official de Legislação Portuguesa redigida pelo Desembargador António Delgado da Silva, Anno de 1844-1845, Lisboa, Imprensa Nacional, Lisboa, 1845, p. 728.

${ }^{27}$ Confira-se MOUTINHO DOS SANTOS, M. J.: A Sombra e a Luz. As prisões do Liberalismo, Porto, Edições Afrontamento, 1999, p. 201. 
presidente, pelo presidente da câmara municipal, pelo provedor da misericórdia, pelo pároco da freguesia mais populosa do distrito, por um médico e ainda por dois cidadãos escolhidos, de dois em dois anos, pela câmara municipal entre os 40 maiores contribuintes. No caso das cadeias comarcãs, previa também a criação de comissões, presididas pelo presidente da câmara e constituídas pelo administrador do concelho, pelo provedor da misericórdia, pelo pároco da freguesia mais populosa da cabeça do concelho, por um médico e por dois habitantes, escolhidos pela câmara entre os 40 maiores contribuintes. Importa ainda referir que, segundo o disposto no artigo $60 .^{\circ}$, Título XIV, da lei supracitada, a inspeção e o governo das cadeias ficavam sob a tutela do Ministério dos Negócios Eclesiásticos e da Justiça ${ }^{28}$.

O papel exercido pelos administradores dos concelhos a nível da inspeção e do melhoramento das cadeias esteve na origem de relações nem sempre fáceis com as câmaras municipais, que continuavam responsáveis pelas obras nas prisões. Esta conflituosidade resultava da dificuldade em garantir a salubridade e limpeza do espaço prisional sem a realização de melhoramentos, que, como já foi referido, nem sempre estavam ao alcance dos cofres municipais ${ }^{29}$. O Código Administrativo de 1842 , de acordo com o número II, do artigo $249 .^{\circ}$, atribuía aos administradores dos concelhos não só o sustento dos presos pobres, mas igualmente a polícia das cadeias ${ }^{30}$. O policiamento destes espaços implicava a inspeção da atividade dos carcereiros, a participação das falhas detetadas, a organização da vigilância da prisão e a colaboração na captura de presos evadidos.

Posto isto, podemos concluir que o combate à pobreza e os mecanismos assistenciais eram controlados, pelo menos num plano teórico, pelo estado liberal, que se mostrou, aliás, pouco empenhado na estimulação da iniciativa privada. A erradicação da pobreza não passou de uma quimera, foi apenas atenuada pela ação das misericórdias, confrarias, ordens terceiras, estas duas mais vocacionadas para auxiliar os seus irmãos, e da própria Igreja. Esta, apesar dos intentos securalizantes oitocentistas, continuou a exercer uma ação fundamental no apoio aos mais carenciados, fruto da abertura demonstrada pelos governantes liberais às ordens religiosas e à sua presença em diversas instituições, como hospitais, o

\footnotetext{
${ }^{28}$ Collecção Official da Legislação Portuguesa, Anno de 1867, Lisboa, Imprensa Nacional, Lisboa, 1868, pp. 273-274.

${ }^{29}$ Sobre as dificuldades financeiras que afetavam os municípios do Minho, entre os finais do Antigo Regime e 1834, consulte-se VIRIATO CAPELA, J: O Minho e os seus Municípios. Estudos económico-administrativos sobre o município português nos horizontes da reforma liberal, Braga, Universidade do Minho. Mestrado de História das Instituições e Cultura Moderna e Contemporânea, 1995, pp. 93-109.

${ }^{30}$ Código Administrativo ..., op. cit., p. 104.
} 
que permitiu superar a inoperância das mesmas e a inexistência de profissionais qualificados. Entretanto, outras instituições despontaram na resposta aos novos problemas sociais, resultantes de uma nova ordem marcada pela industrialização, pelo êxodo rural e pela emergência da classe operária. Assim, por todo o país, vão nascendo creches, lactários, albergues noturnos e asilos para a infância desvali$\mathrm{da}^{31}$. Era o que sucedia em Viana do Castelo, um distrito essencialmente rural que se foi adaptando às transformações ditadas pelo ideário oitocentista.

A afirmação do higienismo explica o surgimento de balneários públicos, dado que a burguesia emergente, defensora acérrima dessa ideologia, empenhase na catequização sanitária dos povos, sobretudo das classes populares, tendo como elemento evangelizador a água ${ }^{32}$. Esta adquire uma importância vital para a limpeza de espaços públicos e privados, dos corpos e da roupa, com o objetivo de extirpar os elementos potenciadores de doenças. Neste novo quadro, uma doença já antiga ganha novas proporções: a tuberculose. Esta enfermidade, que assumiu contornos verdadeiramente pandémicos até meados do século XX, ficou conhecida nos anais da História como a peste branca.

Assim, podemos considerar que, no âmbito da assistência aos mais carenciados, emergem em Portugal novas linhas de atuação, centradas na prevenção da pobreza, que se materializaram na criação de asilos para a infância desvalida, na aposta na educação, na repressão da vagabundagem e da falsa pobreza, a par da adoção de medidas profiláticas, designadamente em matéria de higiene pública e privada, para enfrentar doenças e epidemias, sobretudo após os primeiros surtos de cólera na década de trinta de oitocentos.

O estudo das reformas no campo da assistência, levadas a cabo após a imposição da nova ordem liberal, exige do investigador o acesso à produção legislativa que suporta essas alterações, o que, por outro lado, implica disponibilidade para consultar as fontes documentais referentes às diversas entidades envolvidas nesse processo. Surge aqui a primeira dificuldade no trabalho investigativo, visto que, para conseguir informação que se pretende objetiva, o cientista deve atender a dois critérios que garantam o cumprimento desse requisito tão caro a algumas correntes: o espaço e o tempo. As balizas cronológicas são importantes para estabelecer as perenidades e as mutações relativamente a uma determinada realidade

\footnotetext{
${ }^{31}$ Leia-se GUIMARÃES SÁ, Isabel: “Assistência”, in MOREIRA AZEVEDO, C., Dicionário de História Religiosa de Portugal, Lisboa, Círculo de Leitores, 2000, p. 148. Consulte-se igualmente LOPES, M. A.: "Os pobres e a assistência pública", in MATTOSO, J., História de Portugal, vol. V, 1993, pp. 501-515.

${ }^{32}$ Sobre este assunto consulte-se PEREIRA, A. L.; PITA, J. R.: "AA higiene: da higiene das habitações ao asseio pessoal", in VAQUINHAS, Irene (dir.), História da Vida Privada em Portugal, Lisboa, Círculo de Leitores, 2011, pp. 97-100.
} 
histórica. Por sua vez, o espaço impõe-se como uma variável de grande relevância para compreender de que forma as especificidades contextuais condicionam a aplicabilidade de medidas generalistas. Deste modo, podemos estabelecer dois objetivos de estudo distintos, com base na espacialidade: conhecer a aplicação das reformas emanadas do poder ou os particularismos característicos do espaço que nos propomos estudar. Tudo isto sem esquecer o tema central do processo investigativo.

Para o estudo da assistência no norte de Portugal no século XIX, os investigadores terão que se debater com a dispersão e o caráter por vezes contraditório das fontes. No entanto, não podem desperdiçar a oportunidade de cruzarem fontes de natureza distinta. Refira-se que não abundam os trabalhos sobre a pobreza e a assistência no Norte de Portugal no século XIX, à semelhança do que acontece em relação às demais regiões do país. No caso do distrito de Viana do Castelo, por nós estudado, que poderá ter um interesse acrescido para os investigadores espanhóis, dada a condição raiana de alguns dos seus concelhos e a elevada presença de galegos em várias localidades do Alto Minho, o aprofundamento da temática em causa aconselha o conhecimento das obras já produzidas, bem como da legislação relacionada com a prevenção e o combate à pobreza. Maria Marta Lobo de Araújo, António Matos Reis, Teodoro da Fonte, António Magalhães, entre outros autores, têm estudado e publicado trabalhos de inegável interesse sobre a obra assistencial de instituições do distrito vianense, pelo que devem ser tidos em devida conta ${ }^{33}$.

\footnotetext{
${ }^{33} \mathrm{Na}$ vasta produção bibliográfica da autoria de Maria Marta Lobo de Araújo sobre a assistência no Alto Minho destacamos LOBO DE ARAÚJO, M. M.: "Pobres nas malhas da lei: a assistência aos presos nas Misericórdias de Vila Viçosa e Ponte de Lima", Cadernos do Noroeste, vol. 11 (2), 1998, pp. 83-114. "Festas e rituais de caridade nas Misericórdias", in Piedade Popular: Sociabilidades, representações e espiritualidades: atas do Colóquio Internacional, Lisboa, Centro de História da Cultura, 1999, pp. 501-516. Dar aos pobres e emprestar a Deus: as Misericórdias de Vila Viçosa e Ponte de Lima (séculos XVI-XVIII), Barcelos, Santa Casa da Misericórdia de Vila Viçosa; Santa Casa da Misericórdia de Ponte de Lima, 2000. Pobres, Honradas e Virtuosas: os dotes de D. Francisco e a Misericórdia de Ponte de Lima (1680-1850), Ponte de Lima, Santa Casa da Misericórdia de Ponte de Lima, 2000. Rituais de caridade na Misericórdia de Ponte de Lima (séculos XVII$X I X)$, Braga, Santa Casa da Misericórdia de Ponte de Lima, 2003. "Nas franjas da sociedade: os esmolados das Misericórdias do Alto Minho (séculos XVII-XVIII)", Diálogos, n. ${ }^{\circ}$ 9:2, 2005, pp. 121-142. "Confrarias", in VIRIATO CAPELA, J. (coord.): As Freguesias do Distrito de Viana do Castelo nas Memórias Paroquiais de 1758. Alto Minho: Memória, História e Património, Braga, Casa Museu de Monção, Universidade do Minho, 2005, pp. 575-579. "Os hospitais de Ponte de Lima na era pré-industrial”, Separata do livro Atas do século XVIII Seminário Internacional sobre Participação, Saúde e Solidariedade - Riscos e Desafios, Braga, ICS, 2006, pp. 481-492. LOBO DE ARAÚJO, M. M.; LOPES ESTEVES, A. P.: "Pasaportes de caridad: Las «cartas de guia» de las Misericórdias portuguesas (siglos XVII-XI), Estudios Humanísticos. Historia, n. ${ }^{\circ}$ 6, 2007, pp. $207-$ 225. A Misericórdia de Monção: fronteira, guerras e caridade (1561-1810), Braga, Misericórdia de Monção, 2008. "Pequenos e pobres: a assistência nas Misericórdias portuguesas da Idade Moderna",
} 
O conhecimento do papel desempenhado pelas autoridades administrativas no domínio da assistência exige o acesso à documentação por elas produzida. Sendo assim, a ação de governadores civis, administradores dos concelhos e regedores deve ser analisada através de um trabalho de arquivo. Os arquivos dos governos civis, entretanto desmantelados em Portugal, permitiam, através dos seus diferentes fundos, uma informação mais concentrada sobre a orgânica do poder administrativo neste segmento. Por outro lado, a partir dos fundos da correspondência recebida e expedida, é possível traçar a linha comunicacional, claramente hierarquizada, que seguia uma ordem descendente, em termos de jurisdição e de aplicação de medidas, e outra ascendente, que seguia a tendência contrária.

\section{Figura 1}

Ministério do Reino $\rightarrow$ Governo Civil $\rightarrow$ Administradores dos Concelhos $\rightarrow$ Regedores

Nem sempre é possível construir esta cadeia de comunicação e nem sempre o investigador consegue aceder à informação produzida recorrendo a todos os canais envolvidos. No caso, por exemplo, da elaboração de mapas de pobres e da distinção entre verdadeiros e falsos pobres, seria fundamental que este processo respeitasse o papel de todas as entidades envolvidas, designadamente do regedor de freguesia, que estava na base do sistema. O mesmo se pode dizer acerca da assistência aos presos, aos doentes, aos idosos, aos estrangeiros e à infância desvalida. Contudo, dificilmente os investigadores encontrariam estes dados concentrados nos arquivos dos governos civis. Esta circunstância exige do investigador uma maior flexibilidade na

in LOBO DE ARAÚJO, M. M.; FERREIRA, M. F. (Orgs.), A infância no universo assistencial da Península Ibérica (sécs. XVI-XIX), Braga, Instituto de Ciências Sociais, 2008, pp. 135-149. Da autoria de Teodoro da Fonte destacamos os trabalhos relacionados com a infância desvalida AFONSO DA FONTE, T.: O abandono de crianças em Ponte de Lima (1625-1910), Viana do Castelo, Câmara Municipal de Ponte de Lima; Centro de Estudos Regionais, 1996. No limiar da honra e da pobreza. A infância desvalida e abandonada no Alto Minho (1698-1924), Vila Praia de Âncora, Ancorensis e Neps, 2005. "Rituais, encenações e estratégias familiares no Alto Minho. As crianças expostas nas Rodas/Hospícios ao longo do século XIX”, in IV Congresso Histórico de Guimarães. Do Absolutismo ao Liberalismo, vol. IV, Braga, Câmara Municipal de Guimarães, 2009, pp. 165-191. De António Magalhães destacamos o seu trabalho sobre a Misericórdia de Viana do Castelo. MAgAlHÃeS, A.: Práticas de caridade na Misericórdia de Viana da Foz do Lima (séculos XVI-XVIIII), Viana do Castelo, Santa Casa da Misericórdia de Viana do Castelo, 2013. "Crianças pobres e doentes: a população jovem como objeto das práticas de caridade na Santa Casa da Misericórdia de Viana Foz do Lima (séculos XVI-XVIII), in LOBO DE ARAÚJO, M. M.; FERREIRA, M. F. (Orgs.), A infância no universo assistencial da Península Ibérica (sécs. XVI$X I X)$, Braga, Instituto de Ciências Sociais, 2008, pp. 111-133. Saliente-se o trabalho desenvolvido sobre a Misericórdia de Ponte da Barca SOUSA PEREIRA, M. D.: Entre Ricos e Pobres: a atuação da Santa Casa da Misericórdia de Ponte da Barca (1630-1800), Braga, Santa Casa da Misericórdia de Ponte da Barca, 2008. 
gestão do tempo, pois obriga à consulta de fundos documentais que se encontram dispersos por vários locais. Alguns dos fundos dos governos civis estão nos arquivos distritais, como acontece, por exemplo, com o arquivo do governo civil de Braga. Os fundos da administração dos concelhos estão à guarda dos arquivos municipais, que conservam, aliás, séries documentais riquíssimas, para além dos livros de correspondência com os governadores civis, câmaras municipais e regedores. Atente-se no caso do Arquivo Municipal de Ponte de Lima, concelho que integra o distrito de Viana do Castelo, cuja documentação disponível propicia diversas áreas de trabalho no âmbito da assistência e da pobreza. Uma das secções deste fundo, com o título Estabelecimentos de Piedade, Beneficência e Ensino Público, subdivide-se em três subsecções: Irmandades e Confrarias, composta por 311 unidades, 22 livros, quatro cadernos e 296 maços de documentos; Juntas de Paróquia; e Saúde e Assistência, que inclui uma série constituída por atestados de pobreza ${ }^{34}$. A secção Administração do Concelho contém seis subsecções, que refletem a panóplia de atribuições exercidas por esta entidade até à sua extinção em 1924. Para além da ação do governador civil, administradores dos concelhos, há que salientar o papel dos regedores, cujos fundos se encontram, na sua maioria, à guarda dos arquivos municipais.

A construção do conhecimento sobre a realidade social e os recursos assistenciais não se pode apoiar unicamente em documentos legislativos emanados do poder central ou nas fontes produzidas pelo poder administrativo. Misericórdias, confrarias e ordens terceiras continuam a desenvolver a sua ação caritativa, guiada por valores espirituais, ainda que condicionada pelo controlo exercido pelos organismos administrativos saídos do ordenamento liberal pós-1834. Essa circunstância reflete-se nos seus fundos documentais, que não devem ser descu$\operatorname{rados}^{35}$. O interesse dos fundos das misericórdias do Alto Minho varia de instituição para instituição, dependendo da dimensão das séries documentais, da sua relevância temática e da importância concedida ao património arquivístico pelos dirigentes das organizações que continuam ativas e/ou que têm à sua guarda os acervos documentais ${ }^{36}$.

A riqueza e a diversidade das fontes para o estudo da pobreza e da assistência no século XIX, oriundas dos fundos documentais pertencentes às entidades

\footnotetext{
${ }^{34}$ Estes dados podem ser consultados na página do Arquivo Municipal de Ponte de Lima, que tem o seguinte endereço: http://arquivo.cm-pontedelima.pt/, consultado no dia 14 de setembro de 2013.

${ }^{35}$ Sobre os fundos documentais de arquivos municipais e de misericórdias pertencentes ao distrito de Viana do Castelo leia-se ALVES PEREIRA, M. O.: "Introdução", in Recensamentos dos Arquivos Locais. Distrito de Viana do Castelo, vol. 3, Lisboa, Arquivos Nacionais/Torre do Tombo, 1996.

${ }^{36}$ Sobre os arquivos das misericórdias do Alto Minho consulte-se LOBO DE ARAÚJO, M. M.: "Os arquivos das Misericórdias do Alto Minho: um itinerário de investigação", Cadernos Vianenses, tomo 40, 2007, pp. 357-377.
} 
administrativas e religiosas ou às misericórdias, permitem ao investigador uma visão mais completa destas realidades, ainda que a objetividade do conhecimento obtido só possa ser garantida se nos dispusermos a preencher outros requisitos, de que faremos menção mais adiante. Há que atender ainda aos fundos das próprias instituições que tinham a seu cargo pessoas conotadas com o submundo da pobreza e da marginalidade. É o caso de algumas cadeias, que, apesar das vicissitudes do tempo, conseguiram preservar as provas do seu passado. Através de algumas fontes, é possível constatar a indigência dos que, caídos nas malhas da justiça, sofriam as agruras do cárcere e descobrir os mecanismos utilizados para os socorrer. O mesmo sucede com asilos, hospitais, dispensários, instituições saídas da nova ordem política oitocentista, que dispõem igualmente de fundos próprios que proporcionam uma abordagem ainda mais completa sobre estas temáticas. No caso particular do distrito de Viana do Castelo, estes fundos estão dispersos pelos arquivos municipais das localidades onde estavam sedeadas as instituições. Em Viana do Castelo, sede de distrito e, portanto, localidade onde está instalado o arquivo distrital, também se pode encontrar fundos documentais referentes a instituições vocacionadas para a assistência, como é o caso do Hospital Padre Luís Faria, destinado a acolher padecentes de tuberculose, e dalgumas confrarias vianenses. Saliente-se, porém, que no caso de a instituição continuar ativa, como sucede frequentemente com as misericórdias, os arquivos mantêm-se, geralmente, nas respetivas instalações.

Em jeito de conclusão do "périplo arquivístico", importa salientar que, para o estudo da pobreza e da assistência no período oitocentista no distrito de Viana do Castelo, convirá incluir no roteiro investigativo o arquivo distrital, os arquivos municipais e das várias instituições (confrarias, misericórdias, ordens terceiras, entre outras) e até mesmo arquivos familiares, caso se pretenda tratar, por exemplo, do caso particular do benemérito de uma instituição ou de um legatário. Contudo, não podemos deixar de mencionar as fontes coevas, que nos fornecem descrições mais ou menos exatas da realidade social, económica e política do Minho oitocentista. Autores como Augusto José Vieira, Pinho Leal, Manuel Gomes da Lima Bezerra, Narciso Alves da Cunha, José Cândido Gomes ou Alberto Pimentel, merecem uma análise atenta ${ }^{37}$.

37 LIMA BEZERRA, M. G. de: Os Estrangeiros do Lima, vol. 1, Viana do Castelo, Câmara
Municipal de Viana do Castelo, 1992, Ed. facsimilada de 1785. ALVES DA CUNHA, N. C.:
No Alto Minho. Paredes de Coura, Paredes de Coura, Câmara Municipal de Paredes de Coura,
1879. GOMES, J. D.: As terras de Valdovês: memórias históricas e descriptivas do concelho dos
Arcos de Val de Vez, vol. II, Arcos de Valdevez, Typographia Lusitana, 1899. PINHO LEAL, A.:
Portugal Antigo e Moderno. Diccionário Geographico, Estatistico, Chorographico, Heraldico,
Archeologico, Histórico, Biographico e Etymologico de todas as cidades, villas e freguezias de
Portugal e de grande número de aldeias, vols. 1 a 10, Lisboa, Livraria Editora Tavares Cardoso \& 
Dentro de um espírito positivista, que marca o século XIX, em que o número confere rigor científico ao conhecimento, organizam-se estatísticas a fim de se construírem quadros que permitam a estruturação de análises e a enunciação de soluções mais coerentes e objetivas para a resolução de problemas. A quantificação da informação começou a assumir uma importância cada vez maior com os governos liberais, tendo em vista a obtenção de dados mais rigorosos sobre as atividades económicas, a população e as suas características, de modo a que as autoridades se munissem de instrumentos adequados para combater os problemas que afetavam o país ${ }^{38}$. Com base nos elementos recolhidos, elaboravam-se estudos estatísticos, transformados em meios auxiliares na tarefa de diagnosticar o estado do reino nas suas mais diversas vertentes, e procurava-se definir e promover as reformas julgadas indispensáveis ${ }^{39}$.

Os investigadores passam então a dispor de estatísticas, mais ou menos rigorosas, sobre matérias sociais, organizadas pelas diferentes instâncias do poder. Se por um lado não devem ser ignoradas, também não devem ser sobrevalorizadas, dado o elevado risco de erro. Por conseguinte, o método mais fiável será o cruzamento de dados, pois pode suceder que, sobre a mesma realidade, entidades diferentes obtenham resultados distintos. Se possível, o cruzamento deve ser efetuado com base no mesmo tipo de fonte, de modo a tentar descobrir a origem do erro. Contudo, nem sempre é possível, por exemplo, ter os números respeitantes à pobreza isentos de deturpações, devido ao caminho que percorreram: foram compilados pelo regedor, posteriormente trabalhados pelo administrador do concelho e transmitidos ao governador civil, que, por sua vez, os encaminhou para o poder central.

Com a chegada do século XIX, os jornais tornam-se importantes fontes documentais para a investigação no campo da história contemporânea. As notícias plasmadas nestes documentos têm servido para fundamentar perspetivas sobre os acontecimentos mais marcantes da História de Portugal, sobretudo dos séculos XIX e XX. De facto, os jornais constituem um valioso suporte documental para

Irmão, 1882. VIEIRA, J. A., O Minho Pittoresco, Tomo I, Lisboa, Livraria António Maria Editor, 1886.

${ }^{38}$ Sobre a importância da estatística como instrumento de governação veja-se FOUCAULT, Michel: Segurança, Território, População. Curso dado no Collége de France (1877-1978), São Paulo, Martins Fontes, 2008, pp. 138-139. Sobre as primeiras estatísticas produzidas em Portugal leia-se CORDEIRO FERREIRA, M. E.: "Estatística", in SERRÃO, Joel (dir.), Dicionário de História de Portugal, Lisboa, Iniciativas Editoriais, 1975, pp. 456-462.

${ }^{39}$ A título exemplificativo, a circular de 20 de outubro de 1835 solicitava a todos os governos civis a classificação da população com base na idade, no sexo e na profissão. Veja-se Collecção de Leis e outros documentos officiais publicados desde 15 de agosto de 1834 até 31 de dezembro de 1835, Lisboa, Imprensa Nacional, 1837, pp. 368-370. 
a elaboração de investigações no campo da história política, económica, cultural, religiosa e social.

A relevância que a imprensa tem assumido no campo da investigação histórica não se traduz apenas na realização de trabalhos que têm os jornais como principal fonte documental, mas também no facto de constituir objeto de estudo ${ }^{40}$. Por outro lado, arquivos, bibliotecas e hemerotecas têm contributo para o lugar de destaque no domínio da historiografia, através da organização de catálogos e inventários sobre as suas coleções de jornais, revistas, almanaques e outras publicações. Importa ainda salientar o facto de os entraves colocados à reprodução fotográfica dos jornais não serem tão rígidos como os que se verificam em relação a outros tipos de documentos, o que facilita a tarefa do investigador.

O primeiro jornal publicado no distrito de Viana do Castelo, A Aurora do Lima, nasceu em 1855, sendo rapidamente acompanhado por outros periódicos, alguns dos quais tiveram uma existência efémera. A situação dos mais vulneráveis, ou seja, de crianças, idosos, doentes e, sobretudo, dos presos indigentes, surgia plasmada nas páginas dos jornais daquela circunscrição administrativa. Por vezes, os periodicistas não se eximiam de denunciar a inoperância ou a ineficácia das medidas tomadas pelas autoridades para minorar a desgraça alheia. Um dos problemas que mais inquietava a sociedade oitocentista era a elevada mortalidade dos expostos. A este propósito, o jornal O Lethes escrevia o seguinte em 1866:

Durante o anno que findou em desembro, entraram na roda d'esta villa, 115 expostos. Sendo 57 do sexo masculino e 58 do feminino. Morreram 77, sendo 42 do sexo masculino e 35 do feminino. Sobreviveram por tanto 38 de ambos os sexos! É horrorosa esta mortandade. ${ }^{41}$

No século XIX, a caridade foi dando lugar à filantropia, ou seja, à doutrina que encarava a felicidade humana como uma construção alcançável através da

\footnotetext{
${ }^{40}$ Entre os diversos trabalhos produzidos pela historiografia sobre a imprensa periódica veja-se: FRANCO, G.: A Censura à Imprensa (1820-1974), Lisboa, INCM, 1993. MATOS E LEMOS, M.: Jornais diários portugueses do século XX. Um Dicionário. Nota de Apresentação de Isabel Nobre Vargues, Coimbra, Ariadne/CEIS20, 2006. PENA, A: Salazar, a imprensa e a Guerra civil de Espanha, Coimbra, Minerva Ciências da Comunicação, 2007. TENGARRINHA, J.: Imprensa e Opinião Pública em Portugal, Coimbra, Minerva Coimbra, 2006. NOBRE VARGUES, I.: "Espaço público e história da comunicação contemporânea: os casos Dreyfus,' Guerra dos Mundos' e Watergate",separata de Espaços públicos, Poder e Comunicação, Public Spaces, Power and Communication, organização de Edmundo Balsemão Pires, Porto, 2007, Edições Afrontamento, pp. 197-208. NOBRE VARGUES, I.: "Tesoura, rolha e lápis: os tempos da censura e do combate pelas liberdades de expressão e de imprensa em Portugal" em $O$ (s) tempo (s) dos media. Revista Estudos do século XX, 7, 2007.

${ }^{41} O$ Lethes, 26 de janeiro de 1866.
} 
prática de atos altruístas e humanitários, que teriam como objetivo último atenuar ou mesmo eliminar as injustiças sociais. A conceção do homem caridoso, que auxilia o pobre com a intenção de obter a salvação espiritual, dá lugar à filantropia, entendida como dever social. Valores como beneficência e humanitarismo faziam parte de um corpo de qualidades que deviam ser cultivadas por determinados grupos sociais, nomeadamente pela alta e média burguesia. Estes valores eram postos em prática através de atos de generosidade dirigidos às franjas mais debilitadas da sociedade ${ }^{42}$. Ainda no século XVIII, concretamente em 1793, Leopoldo Berchtold evocou frequentemente a palavra filantropia, considerando que os membros das classes superiores deviam respeitar e dar atenção aos membros mais desfavorecidos da sociedade ${ }^{43}$. Segundo este mesmo autor, os pais deviam entregar aos filhos a responsabilidade pelas ações de beneficência que já praticavam e conduzi-los a locais onde proliferavam os mais necessitados, como, por exemplo, às cadeias ${ }^{44}$.

Uma das formas de manifestação de altruísmo consistia precisamente na dádiva de esmolas aos presos pobres. Tais gestos eram publicitados nas páginas dos jornais, que reservavam o espaço necessário para a exaltação da magnanimidade do doador. Na prática, a concessão de esmolas podia ser motivada pela necessidade de construir ou conservar a imagem social do benfeitor, dado o impacto que estes gestos tinham junto da opinião pública. Todavia, não podemos negligenciar a existência de motivações espirituais, nomeadamente o desejo de obtenção de uma recompensa futura, que passaria pela expiação dos pecados e obtenção da salvação eterna ${ }^{45}$.

Dinheiro, alimento, roupa de cama e de vestir faziam parte das dádivas que os particulares concediam aos pobres com o objetivo de minorar o seu sofrimento. Assim, em ocasiões especiais, como no Natal, por ocasião da celebração

\footnotetext{
${ }^{42}$ Segundo Maria Antónia Lopes, a palavra beneficência era utilizada por escritores religiosos "com o significado de ato de bondade de fazer bem, geralmente atribuído a Deus, ou, também, como manifestação de caridade." Todavia, como refere a mesma autora, em finais de setecentos, generalizou-se em Portugal a versão iluminista do termo, que será adotada pelo Liberalismo, significando uma ação meramente laica, desprovida de qualquer sentido religioso, associada à filantropia. Consulte-se LOPES, M. A.: Pobreza, Assistência e Controle Social em Coimbra (17501850), vol. I, Viseu, Palimage Editores, 2000, pp. 63-64.

${ }^{43}$ BERCHTOLD, L.: Ensaio sobre a extensão dos limites da beneficência a respeito assim dos homens, como dos mesmos animais, Lisboa, Regia Officina Typografica, 1793, pp. 8-9.

${ }^{44}$ BERCHTOLD, L.: Ensaio sobre a extensão dos limites da beneficência a respeito assim dos homens, como dos mesmos animais..., p. 11.

${ }^{45}$ Sobre a relação existente entre a concessão de esmolas e a obtenção de recompensas espirituais leia-se LOBO DE ARAÚJO, M. M.: Rituais de caridade na Misericórdia de Ponte de Lima (séculos XVII-XIX)..., op. cit., pp. 34-44.
} 
de aniversários dos monarcas, ou através de subscrições públicas, eram levados a cabo gestos benfeitores para com os mais carenciados que não passavam despercebidos à imprensa, que os registava e enaltecia. Descreviam-se os jantares, exaltava-se a variedade e a abundância da ementa, em flagrante contraste com a frugalidade que, habitualmente, caracterizava a mesa dos pobres ${ }^{46}$.

No dia 25 de dezembro de 1858, os presos da cadeia de Viana do Castelo tiveram direito a um jantar, promovido por Joaquina Ferreira Maia Queiroz, sendo o gesto recompensado com rasgados elogios e com a exaltação das virtudes da benfeitora no jornal $O$ Vianense:

[...] ação esta que aquella excelente senhora, minorando $o$ sofrimento dos pobres encarcerados, soube dar mais um testemunho dos seus piedosos sentimentos e bondoso coração $0^{47}$.

Digno de nota nas páginas d'O Vianense era o jantar, destinado aos reclusos, que todos os anos tinha lugar na quinta-feira santa, organizado pela Ordem Terceira de São Francisco de Viana do Castelo. No mês de setembro de 1858 e no ano seguinte, foi a vez do Conde da Lousã presentear os detidos com a mesma oferta, a propósito das comemorações de aniversário do rei D. Pedro V, o que lhe valeu aplausos nas páginas dos periódicos vianenses. De igual modo, as doações em dinheiro, como as que foram concedidas pelo Marquês de Saldanha e por Jácome Borges Pacheco Pereira, governador civil do distrito, aos presos pobres da cadeia de Viana do Castelo, em 1861, eram publicitadas e elogiadas pelos jornais ${ }^{48}$.

Apesar de alguma subjetividade que subjaz aos textos publicados, devido ao seu caráter opinativo, pessoal e, por vezes, à influência do comprometimento político, os jornais não deixam de ser uma fonte a ter em conta para aprofundar temáticas no domínio da história social, muito particularmente as relacionadas com a pobreza e a assistência. Até porque em muitas outras notícias havia a preocupação de informar com rigor e objetividade, designadamente quando se tratava de divulgar dados estatísticos ou o balanço da atividade desenvolvida pelas instituições assistenciais.

\footnotetext{
${ }^{46}$ Em dezembro de 1863, a propósito do jantar oferecido aos presos pobres da cadeia de Viana do Castelo, patrocinado pelo Ministro da Marinha, o jornal $O$ Vianense fez uma descrição pormenorizada do "banquete": "constou de boa sopa, excelente cozido e vitela guizada, e de arroz doce e fruta para sobremesa, alem do competente vinho". Leia-se $O$ Vianense, 5 de dezembro de 1863, n. $^{\circ} 858$, não paginado.

47 O Vianense, 27 de dezembro de 1858, n. $^{\circ} 119$, não paginado.

${ }^{48}$ A Aurora do Lima, 4 de março de 1861, n. $^{\circ} 783$, não paginado.
} 
Para além das fontes já elencadas, uma outra emerge no século XIX, e que também pode apoiar documentalmente estudos de caráter científico no domínio da história: a fotografia. Trata-se de um recurso viável para conhecer, nomeadamente, a evolução física dos espaços, as suas condições e a população que albergaram.

Importa ainda assinalar que, mais uma vez em resultado do contributo da Escola dos Annales, se procedeu ao alargamento do conceito de documento, permitindo que este se estendesse a fontes não inscritas, incluindo-se aqui, por exemplo, o estudo dos objetos. Estes, enquanto elementos comprovativos de quotidianos passados, podem ser utilizados sob o ponto de vista investigacional, sobretudo quando o historiador tem a pretensão de os cruzar com as fontes escritas. Assim, uma das formas de promover a extensão do conhecimento histórico para além do universo académico pode passar pela exposição destes objetos, devidamente contextualizados, em espaços públicos.

Deste modo, e no que respeita muito particularmente ao distrito de Viana do Castelo, os investigadores devem proceder a um cruzamento de fontes escritas diversificadas e integradas em diferentes espaços: arquivos públicos e privados, bibliotecas e centros de documentação. Poderão ainda, como já salientámos, recorrer aos arquivos das próprias instituições. As fontes são abundantes e muitos dos acervos estão por trabalhar, dada a proliferação de instituições saídas do ideário liberal, algumas já estudadas noutros pontos do país, como os asilos para a terceira idade, dispensários, balneários ou albergues noturnos. Esta circunstância obriga o investigador a estabelecer limites temáticos. Aqui os critérios poderão ser demarcados pelo estudo de uma instituição, um problema social ou um grupo de assistidos. A par deste critério restritivo, outros poderão ser impostos: o espacial - estudar uma freguesia, uma vila, uma cidade ou o distrito no seu todo, o que apenas pode ser feito num cenário onde as fontes escasseiam ou no âmbito de um projeto alargado; e o temporal, cujos limites poderão estar pendentes dos dois anteriores. Impostas as barreiras delimitativas para o desenvolvimento do trabalho investigativo, aconselha-se uma metodologia baseada na pesquisa cruzada de fontes pertencentes a diferentes fundos e séries documentais. Este cruzamento impõe-se pela necessidade de construção de um conhecimento objetivo. Para isso, o investigador deve atender à origem das fontes, aos seus autores e à intencionalidade que subjaz a todo o processo discursivo presente nas mesmas. Com isto podemos considerar que o historiador social deve tomar precauções acrescidas, pois a larga maioria das fontes é escrita com um sentido de verticalidade, ascendente ou descendente, consoante o destinatário. Por conseguinte, a escrita deve ser encarada como uma fonte de poder, pois no século XIX a escrita era privilégio de um número reduzido de indivíduos. Assim, o historiador social acede a uma determinada realidade através de leituras enviesadas e subjetivas, 
quase sempre comprometidas com o poder. Como não dispõe da possibilidade de recorrer a fontes orais, deve proceder a uma análise de conteúdo, no sentido de compreender a lógica interna do discurso, analisar a argumentação desenvolvida e procurar entender as palavras e expressões mais frequentes. Tudo isto sem descurar o contexto em que fonte foi produzida e, sempre que possível, seguindo um processo baseado no cruzamento de fontes e na leitura de documentos coevos, bem como na bibliografia nacional e internacional que se ocupa das temáticas que são objeto de estudo.

Por norma, "os pobres não falam", pelo que dispomos apenas das interpretações dos seus interlocutores. Aliás, conseguimos aceder apenas a uma parcela desses pobres, àqueles que, por alguma razão, foram referenciados pelas instituições e, por essa via, acabaram por perpetuar o seu nome na História. Colocamse então algumas questões, que se afiguram pertinentes, e podem ser motivos de reflexão: Chegarão os historiadores à verdadeira dimensão da pobreza ou ficarão pela interpretação das fontes produzidas por uma estrutura extremamente hierarquizada, dominada pelo poder administrativo? Poderemos conhecer verdadeiramente a assistência através das instituições? Poderemos conhecer os verdadeiros contornos da pobreza envergonhada? O caminho a seguir não passará pelo desenvolvimento da história cultural?

Mesmo num território delimitado como o distrito de Viana do Castelo, onde as instituições de assistência estão já cartografadas, há uma massa de gente anónima cujo nome, passado e estória, a História esquecerá, mas cuja existência não se pode simplesmente ignorar: são os pobres que conseguiram sobreviver à custa do amparo da família ou da vizinhança e os que, abandonados à sua sorte, não conseguiram resistir ao destino traçado pela miséria. 